\title{
SOME ASPECTS OF SHRIMP FARMING SYSTEMS AND SHRIMP PRODUCTION MANAGEMENT: BANGLADESH PERSPECTIVE
}

\author{
Sarkar, A. K., M. N. Islam ${ }^{1}$ and F. H. Ansary ${ }^{2}$ \\ KMI International-Organic Shrimp Project, Bangladesh; ${ }^{1}$ Department of Zoology, Rajshahi University; \\ ${ }^{2}$ ACI Limited, Bangladesh
}

\begin{abstract}
Shrimp is one of the leading exportable seafood products in Bangladesh. In the 2017-2018 financial year the country has exported 36168 MT products. Present research work was conducted in three Upazilas (Kaliganj, SyamNagar and Assasuni) in Sathkira district. Three different farming practices (organic, traditional and control) were selected for the research programme. The working farmers in the farming practices were found to follow the traditional farming in the early times. Average production was found $275 \mathrm{~kg} / \mathrm{ha}$ in the traditional farming practices. This is the lowest shrimp production in the world. Reasons are lack of better technology, dearth of quality seed and feed and effect of shrimp diseases. Small-scale organic shrimp farming practice was found to maintain better production and profitability in the three experimental Upazilas. Three different farming practices (viz. organic, traditional and control/ extensive farming) were taken under interview to collect data. A comparison of the production ( $\mathrm{kg} / \mathrm{ha} / \mathrm{yr}$ ) of three years' time (2012 to 2014) was made for analysis in the study. The highest production rate was recorded in organic shrimp farming. It was $13.16 \%$ higher than the traditional and $15.14 \%$ higher than the control/extensive shrimp farming system. Traditional shrimp farming production was $1.98 \%$ higher than that of the control/extensive shrimp farming. Percentage of gross sell of organic system was $14.01 \%$ higher than traditional and $15.89 \%$ higher than that of the control/extensive shrimp farming. The traditional shrimp gross sell was $1.87 \%$ higher than the control shrimp. Interviews and PRA (Participatory Rural Appraisal) method were used for the collection of data. The main research question was 'effect dose' on the overall production, income and impact on biodiversity. Recording data showed that the organic farming practice is more sustainable and environmentally sound system. Organic farming system showed less input cost and higher production value. Organic shrimp farming system increases image value of Bangladesh in the international market.
\end{abstract}

Key wards: Organic; Traditional; Extensive Shrimp farming; Production; Income; Biodiversity.

\section{INTRODUCTION}

The shrimp sector has become very important in Bangladesh. It is highly potential to improve the economy of the country. The sector has contributed to the employment and community development in the coastal regions of Bangladesh.

The development of commercial shrimp farming has initiated national and international debate in recent years on its environmental consequences and social costs. The shrimp culture in Bangladesh is unplanned and led to environmental degradation in the water and soil quality. It has reduced agricultural land and soil fertility, cattle production and grazing land (UNEP 1999). The rice farming is suffered by prolonged water logging derived from extended shrimp seasons (Bhattacharya et al. 1999, FFP 1999). Poor farm management practices are considered responsible for low shrimp production (Nuruzzaman et al. 2001, Huntington 2003). Destructive methods of shrimp Post Larvae (PL) collection from the wild condition have significant impacts on coastal biodiversity (FFP 1999, World Bank/NACA/WWF/FAO 2002).

Over the last five to six years, the industry has achieved substantial progress in the understanding of complex interactions between environment and economy (Nuruzzaman et al. 2003). Implementing measures to reduce negative impacts already been started. Changes include the exodus of outsider entrepreneurs and the return of small land owners to shrimp farming, splitting of large shrimp farms, use 
of hatchery Post Larvae (PL) as shrimp seed, integrating rice and fin fish with shrimp, and no further conversion of mangrove forest into shrimp farms (Nuruzzaman et al. 2003).

Government initiatives include a National Fisheries Policy 1998 restricting any further encroachment on mangrove forests for shrimp farming, and the banning of the wild shrimp PL collection in 2000. This was aimed to reduce the loss of aquatic biodiversity and in the Sundarbans Reserve Forest Area.

Shrimp Action Plan Studies (2002) under the Fourth Fisheries Project of Department of Fisheries, Review and Future Development Studies (2003) and the recent formulation of a Shrimp and Coastal Aquaculture Strategy (2004) are noteworthy among such initiatives. The Ministry of Fisheries and Livestock endorsed Shrimp Action Plan recommendations in 2003 and started 'working' under the FFP. The DOF started to provide alternative livelihood support to the displaced shrimp fry collectors. In 2004, the DOF developed a draft Strategy and Action Plans on 'Shrimp and Coastal Aquaculture Development'. At the beginning to stabilize the programme faced critics' to continue to recycle old information (from the 1980s and 1990s). The present work has been envisaged to introduce the background of the programme at a glance. This work has been divided into two subheadings: Development of shrimp farming in Bangladesh and Shrimp production and exports.

\section{Development of shrimp farming in Bangladesh}

Shrimp culture is an ancient practice in the coastal areas (Khulna, Satkhira, Bagerhat and Cox's Bazar). In the past, people trapped tidal water in low-lying intertidal lands by constructing small dykes. They used to harvest shrimp and finfish after three to four months of the dyke construction.

There was no stocking of fry under this system. Only wild seeds of shrimps like black tiger shrimp (Penaeus monodon), brown shrimp (Metapenaeus monoceros), Indian white shrimp (Fenneropenaeus indicus) and Giant Fresh water shrimp (Macrobrachium rosenbergii) were used.

Because of high demands and rising price, shrimp farms were used to establish in the peripheral lands near the mouths of coastal rivers during the 1970s. By seeing the success of the early farmers, general mass became encouraged to come forward. The shrimp Ghers (local name for a shrimp farm) started to establish on land inside the saline water protection embankment. From the late 1970s to early 1980s, the shrimp culture system was expanded steadily. The farmers began to make selective stocking of shrimp post larvae (PL) caught from the wild habitat. This attempt created a new work opportunity to the coastal peoples. From the mid-80s, the Government launched infrastructure development programmes (IDP) together with improved technology dissemination (IDP) and fiscal incentives for producers and processors. International development partners (WB, ADB, FAO, ODA) supported the industry with credit and technical assistance (1979 and 1999). There were some over-ambitious initiators. They started to setup semi-intensive shrimp farms with imported PL. In 1994 (when white spot disease spread throughout the semi-intensive farms and into extensive farms), the most investors incurred heavy losses in the successive years.

In 1998 the government withdrew the shrimp licensing system and many local landowners refused to renew old lease deeds for outsiders. The capital losses from shrimp disease and growing noncooperation from local landowners made it difficult for the outsiders. The land owners started to split up large farms into smaller units. Consequently, large-scale commercial shrimp farming was gradually replaced by small holders shrimp farming (managed predominantly by local small landowners).

Freshwater shrimp farms in rice fields are found mainly around the coastal districts with some extension into inland districts with perennial water bodies. The main environmental problem associated with the farming system was the 'decline' of snail population. The snails were used as shrimp feed. 
'Drainage congestion created by unplanned construction' was the main obstacle to the shrimp farming system in the wetland areas.

\section{Shrimp Production and Export}

Bangladesh produced an estimated 65,579 mt of farmed shrimp in 2001-02 (DOF 2003). This stands about $5 \%$ of the world's farmed shrimp production. There are two main shrimp species cultured in Bangladesh. Penaeus monodon (the black tiger shrimp locally 'bagda') contributed about $70 \%$ and Macrobrachium rosenbergii (Giant freshwater shrimp locally 'golda') contributed about 15\% production. The remaining 15\% came from the species Metapenaeus monoceros (Horina or brown shrimp), Fenneropenaeus indicus (chaka or Indian white shrimp) and Penaeus semisulcatus (green tiger shrimp). During the early 1990s, Bagda was the dominating species contributed more than $80 \%$ while golda contributed only 5 to $7 \%$. However, during the last 15 years total shrimp production has increased at a rate of about $20 \%$ per year; and much of this growth attributed to a horizontal expansion of the farming area, particularly for golda.

The article attempts to provide a more impartial assessment of the sector's main features and potentials which may prove useful in preparing appropriate development plans for the sector in future.

\section{MATERIAL AND METHODS}

The methods used during study period have been described under different sub headings like Baseline survey, Focus group discussion (FGD), Key person selections, Case Study, Demonstration for the pond farmers, Impact assessment and Data processing and analyses.

\section{Baseline survey}

A questionnaire was developed for 'baseline survey'. Data entry was made in Microsoft excel sheet accordingly. Primarily, a field survey was carried out with the questionnaire and then the information was processed as per the need of the applying practices. The information collected was recorded in consultation with organic shrimp project (OSP) representatives. Forty five farmers were selected for the three sub stations (Kaliganj, Syam Nagar, Asasuni) in Sathkhira district (Table 1). Fifteen farmers were interviewed in each of the sub stations. The people of OSP cooperated to select the farmers for the 'questionnaire survey' according to the convenience of the participating farmers. During the survey interview, open discussion was made with the farmers on the selected ponds. The information in the questionnaire were fed into the computer in Microsoft excel for analysis.

Table 1. Number of farms and area (ha) studied.

\begin{tabular}{l|cc|cc|cc}
\hline $\begin{array}{l}\text { Studied } \\
\text { Upazila }\end{array}$ & $\begin{array}{c}\text { No of } \\
\text { Organic } \\
\text { Farm }\end{array}$ & $\begin{array}{c}\text { Organic Farm } \\
\text { Area (ha) }\end{array}$ & $\begin{array}{c}\text { Traditional } \\
\text { Farm (No) }\end{array}$ & $\begin{array}{c}\text { Traditional } \\
\text { Farm Area (ha) }\end{array}$ & $\begin{array}{c}\text { Control } \\
\text { Farm (No) }\end{array}$ & $\begin{array}{c}\text { Control Farm } \\
\text { Area (ha) }\end{array}$ \\
\hline Assasuni & 5 & 3.1 & 5 & 2.6 & 5 & 4.2 \\
Kaliganj & 5 & 8.3 & 5 & 7.5 & 5 & 7.6 \\
Shyamnagar & 5 & 3.4 & 5 & 4.2 & 5 & 6.6 \\
\hline Total & $\mathbf{1 5}$ & $\mathbf{1 4 . 8}$ & $\mathbf{1 5}$ & $\mathbf{1 4 . 3}$ & $\mathbf{1 5}$ & $\mathbf{1 8 . 4}$ \\
\hline
\end{tabular}

Focus group discussion (FGD)

FGD was conducted through an 'open group discussion meeting' with farmers in the field. Three groups of farmers were selected in the three-sub stations with three different culture practices (viz. Organic, Traditional and Control farming). Each group was formed with 10-15 farmers. In the groups, there were three different culture practicing farmers. They were of different age groups from 19 to 58 
yrs). During the FGD open practices, questions were asked to all participants on shrimp farming practice in their communities. During this focus group discussion, the farmers were asked on comparison between paddy and shrimp framings; effects on ecology and on biodiversity in different shrimp farming practices were also among other questions. After the long discussion they came to a consensus.

\section{Key person selections}

To obtain the expert opinion, some key persons were selected in the different sub-stations of different categories. The sub-station (Upazila) fisheries officers and social elite persons were selected as key persons. They were discussed in personal meetings and the same questionnaires, as were given to the farmers, were given to them for the collection of information. In addition, they were also asked supplementary questions in relation to different farming practices. The supplementary questions were asked mainly on 'income' and 'production' of the farm. The NGO representatives were asked on their field activities. The social elite persons were also asked questions on the local fellow farmer's activities on their shrimp production systems. The Department of Fisheries (DoF) keeps the records/documents on the 'income' and 'production' of shrimps Upazila-wise and yearly basis.

\section{Case study}

Case studies were also conducted with the three categories of farmers of the three Upazilas. The educated and proper competent farmers were selected for the case study. Semi structured interview processes were followed during the case study. All 45 farmers used to keep their farm-records on inputs use, labour use, PL stocking, shrimp sales and miscellaneous records in the pond-record books, which were checked quarterly. During the case study, the farmers presented their opinion freely. At the end of the 'culture season', a workshop was organized regularly with the 45 farmers to record the differences in the three farming practices. Camera and tape recorder were used during the information collection. Information collections were rechecked regularly and quarterly. Baseline questionnaires were used to collect yearly information from the 45 farmers at the end of the each 'culture season'. Duration of the survey lasted for three years long from the years 2012 to 2014.

\section{Data processing and analyses}

Three-year data from the 45 ponds were collected regularly as per the study plan. The 'case study', 'key persons' and 'focus group discussion' data were collected at the time of interview with different stakeholders. The collected data were analyzed following different statistical methods and finally prepared a report accordingly. Data were collected and sorted in Microsoft Office Excel programme. Pivot tables were established to prepare the data for exporting into a statistical programme. Statistical analysis was made by using the JMP8 software package by SAS Corporation. Data collected throughout the study period (2012-2014) were analyzed to detect differences among three treatment levels (organic, traditional and control) of the experimental systems.

\section{RESULTS AND DISCUSSION}

Results are described based on the observations, interviews and discussions with the farm employees. Data analyses were made on the production costs and the sales of the products in different shrimp farms. A statement is made in comparison to the operating cost/ha/yr for three shrimp farming practices in Bangladesh from the years 2012 to 2014. The higher operating cost occurs in traditional shrimp farming than in the other farming. Operating cost depends on the use of different inputs, lease value, PL and over all maintenance practices (Table 2). These cost values vary from year to year. Three years data (Table 3) showed that the production cost was highest in the lease value $48.52 \%$ than the Post 
larvae (PL) cost (39.40\%) and the input cost (12.34\%). The lowest cost was $7.74 \%$ for the maintenance practices.

Table 2. Operating costs (per hectare assessment) of different items (Input, lease, PL and maintenance cost) for the three-years duration of the study in different (Organic, traditional and control) shrimp farms.

\begin{tabular}{lcccc}
\hline Operating Cost & Organic & Traditional & Control & Total \\
\hline Input & 44391.89 & 92402.1 & 0 & 136793.99 \\
Lease & 182837.84 & 215443 & 139510.87 & 537791.71 \\
PL (Post larvae) & 72175.67 & 169099.3 & 106739.13 & 348014.1 \\
Maintenances & 25473.05 & 32587.04 & 27782.74 & 85842.83 \\
\hline
\end{tabular}

In case of the input cost, control farming required no cost. The traditional farm had higher cost (35.09\%) than organic farming. Regarding the lease cost, organic and traditional farming lease value was the same, but it was $8.05 \%$ higher than control farming practices. PL cost was $27.85 \%$ higher than organic and $9.93 \%$ higher than control shrimp farming. The maintenance cost of traditional farming was $8.28 \%$ higher than organic and $5.59 \%$ higher than control practices. Control is also $2.69 \%$ higher than organic farming.

Table 3. Comparative operating cost (BDT/ ha) for three years (2012-2014) in $\mathrm{O}$, $\mathrm{T}$ and $\mathrm{C}$ shrimp farming practices.

\begin{tabular}{lccc}
\hline Years & Organic & Traditional & Control \\
\hline 2012 & 108418.92 & 164379 & 89261 \\
2013 & 109141.89 & 169021.68 & 90728.26 \\
2014 & 107317.57 & 176130.77 & 94043.48 \\
\hline Total & $\mathbf{3 2 4 8 7 8 . 3 8}$ & $\mathbf{5 0 9 5 3 2}$ & $\mathbf{2 7 4 0 3 3}$ \\
\hline Average Cost/ha/yr. & $\mathbf{1 0 8 2 9 2 . 7 9}$ & $\mathbf{1 6 9 8 4 4 . 0 0}$ & $\mathbf{9 1 3 4 4 . 3 3}$ \\
\hline
\end{tabular}

The traditional shrimp farming expense was $16.65 \%$ higher than that of the organic and $21.24 \%$ higher than that of the control shrimp farming. The organic shrimp farming expense was $4.54 \%$ higher than that of the control or extensive shrimp farming.

\section{$P$. monodon production statements in the three different shrimp farming practices $(\mathrm{O}, \mathrm{T}$ and $\mathrm{C})$}

During the study from 2012 to 2014, it was found that most of the P. monodon production occured in organic farming followed by traditional and control shrimp farming (Fig. 1). The P. monodon production depended on the nature of ecosystems of pond/gher. Organic farm was seen to serve all parameters to make pond ecosystem friendly.

In case of organic farm, production of P. monodon was $22 \%$ higher than that of the traditional farming and $29 \%$ higher than that of the control farming. On the other hand, the traditional shrimp farming was $9 \%$ higher in $P$. monodon production than that of the control farming system. 


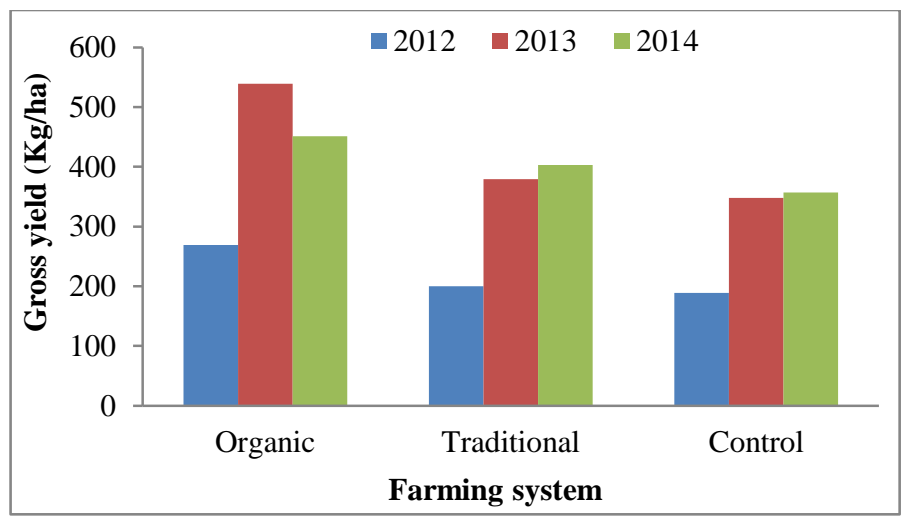

Fig. 1. Production (kg/ha/yr) of P. monodon in different farming culture systems during the years 2012-2014.

\section{Comparisons of three years overall production in three different farming systems}

In comparison to the production in $\mathrm{kg} / \mathrm{ha} / \mathrm{yr}$, during the years from 2012 to 2014, the highest production occured in the organic shrimp farming than in the other farming practices (Fig. 2). Organism growth was well recorded in pond or gher ecosystem. The experimental units (pond/gher) were with full of proper natural nutrient materials. Organic shrimp farming production was $13.16 \%$ higher than the traditional and $15.14 \%$ higher than that of the control shrimp farming. Traditional shrimp farming production was $1.98 \%$ higher than that of the control shrimp farming.

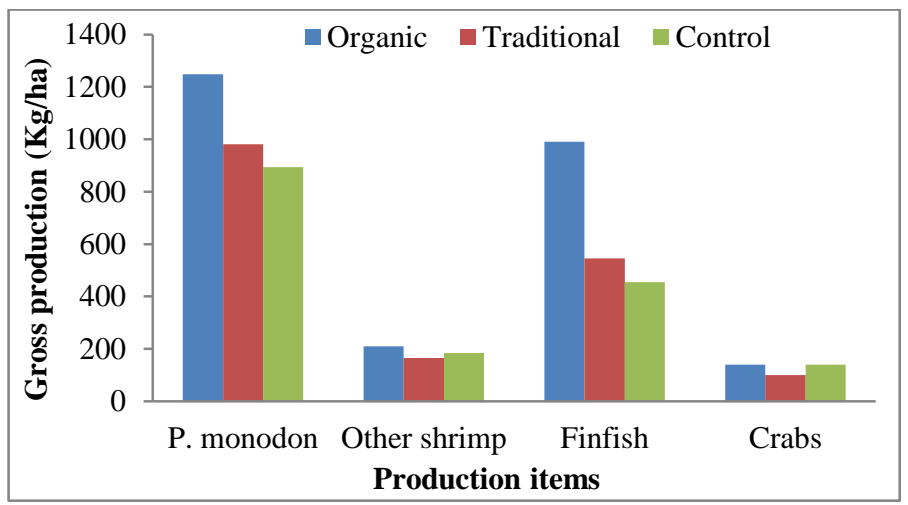

Fig. 2. Overall production in different farming system from 2012 to 2014.

\section{Profit difference in the three different shrimp farming practices}

In comparison to the income recorded (from the years 2012 to 2014), the highest income was found to occur in the organic shrimp farming than in the other farming practices. The results show that highest income ha/yr. was in the organic shrimp than traditional and control shrimp farming in the total duration of the experimental years from 2012 to 2014 (Table 4). Percentage of gross sale resulted from the organic farming was $14.01 \%$ higher than traditional and $15.89 \%$ higher than that of the control shrimp farming. The traditional shrimp gross sale was $1.87 \%$ higher than of the control shrimp farming practices.

Table 4. Hactor-wise comparative shrimp gross sells in taka among the three different culture systems.

\begin{tabular}{lccc}
\hline Year & Organic & Traditional & Control \\
\hline 2012 & 279450 & 201020 & 189150 \\
2013 & 532770 & 330850 & 319510 \\
2014 & 462160 & 330036 & 297978 \\
\hline Total & $\mathbf{1 2 7 4 3 8 0}$ & $\mathbf{8 6 1 9 0 6}$ & $\mathbf{8 0 6 6 3 8}$ \\
\hline
\end{tabular}


In the context of Bangladesh, few literature is available relating to the subject matters of the present article to be taken to the question of discussion. Some important points are noted from the results of the study in a nutshell (Fig. 3). These points could be considered as the part of the discussion. Some reliable and practical observations are stated below which were recorded when the field studies were conducted.

In the research observation and results, it is found that biodiversity as a whole is severely affected when the traditional farming systems were practiced. The traditional farmers used different kinds of insecticides (like heledon, thiodin and Indian oil) before pond preparation to kill the organisms unwanted to them in the pond ecosystem. They also used the same kinds of insecticides at the end of the culture-season to harvest all kinds of their target animals (shrimp, fish, ell, crabs and other invertebrate animals). The indiscriminate doses of the insecticides were used by different farmers. The soil fertility was severely affected as a result of frequent uses of the high doses. Consequently, their production costs became higher day by day in every year. The farmers used pesticides during their field culture to protect the shrimp from the pest attacks. The traditional farmers also mentioned that they did not get shrimp or fish from the natural sources what they got before. During focus group discussions and key informent interviews, the same opinon was also received from the farmers and from the key informers.

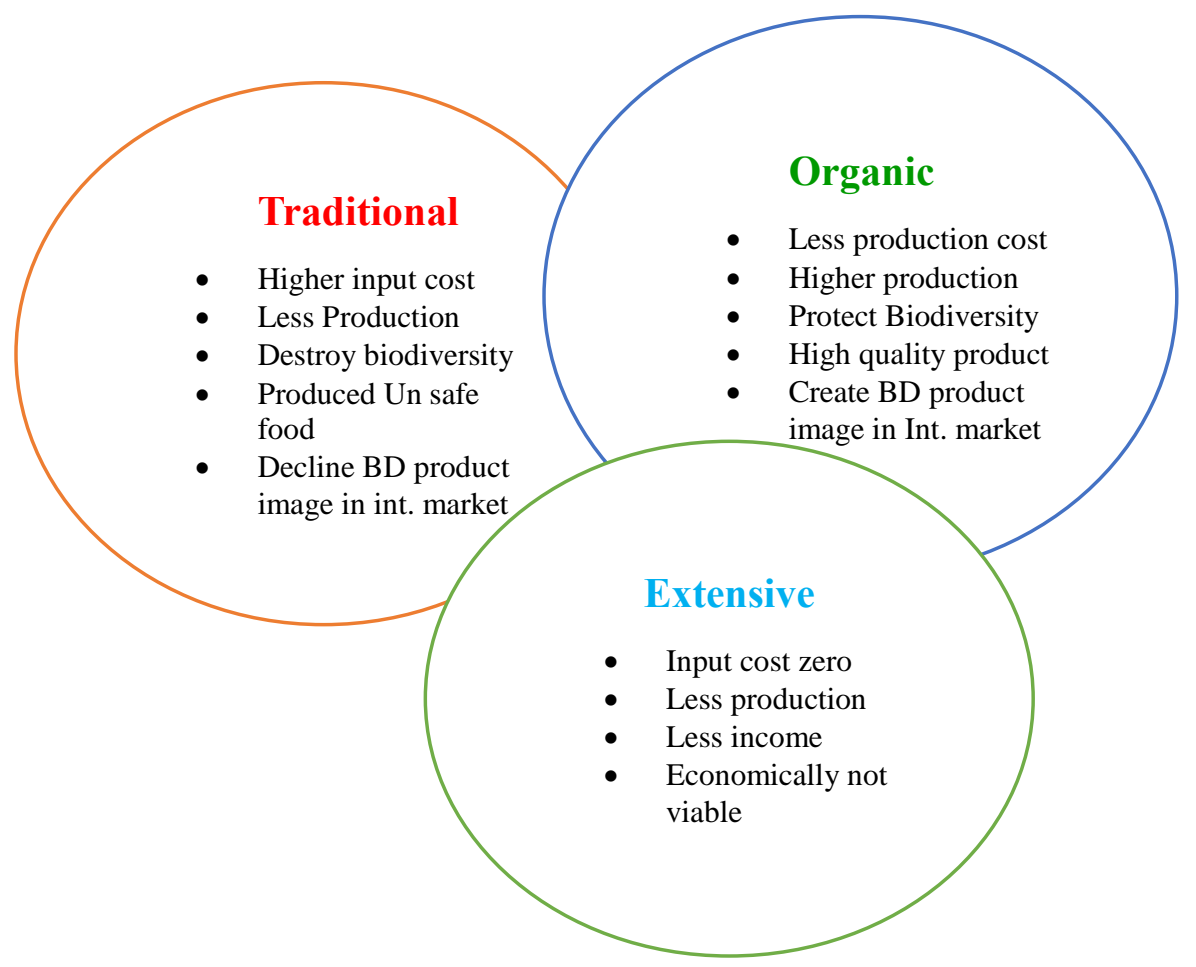

Fig. 3. Some important facts are summarized in the three studied farming models (Traditional, Organic and Extensive) in the article to differentiate their importance/significance in the management of shrimp production in Bangladesh.

In case of organic standard dose (farming system), there was some restictions to allow the use of pesticide, insecticide or any other chemical inputs. Random inorganic fertilizer was also not allowed for the organic farm operation, only certifed organic inputs were allowed to use prior to the approval from the certificatin body. The farmers in the organic farming system were advised (in making the organic standard) to take initiative in protecting biodiversity as well as ecology of the the farming system as a whole. The farmers in the organic farming system were not allowed to stock wild catch PL. The organic farmers were allowed to use only organic certified feeds, but not any kind of artificial food. 
In the control or extensive farming system, the farmers were found to use any kind of input indicriminately in their farms. They followed the premitive culture practices. Every year farmers get their ponds dry at the end of the culture season. After the ponds being dried, for 15-20 days continuously, they allowed to enter the water in the farm and accordingly they used to stock the PL either from hatchery or from the wild catch.

In the three different farming models, it is found that the organic shrimp farming system stands more viable in almost all respects. It is due to less production cost, higher production rate and higher sells in comparison to the traditional and extensive farming models. On the other hand, it is also observed that in terms of the protection of biodiversity and ecology, the farming system is more appropriate than traditional farming.

\section{REFERENCES}

Bhattacharya, D., M. Rahman and F.A. Khatun. 1999. Environmental Consequences of Structural Adjustment: Towards Sustainable Shrimp Culture in Bangladesh. Centre for Policy Dialogue, Bangladesh. CDP Occasional Paper Series No. 2. 37 pp.

DOF. 2002. Shrimp Aquaculture in Bangladesh: A Vision for the Future - an output of the Shrimp Action Plan. FFP/DOF and DFID, Government of Bangladesh., pp. 24-40.

DOF. 2003. Information Sheet on Annual Shrimp and Fish Product Export provided by Principal Scientific Officer. Quality Control Wing, Department of Fisheries, Ministry of Fisheries and Livestock, Government of Bangladesh., pp. 32-45.

DOF. 2004. Draft Shrimp Strategy. FFP, DOF, Government of Bangladesh. 23 pp.

FFP (Fourth Fisheries Project). 1999. Fourth Fisheries Project, Project Proforma. Department Of Fisheries, Government of Bangladesh. 203 pp.

FSRFDS (Fisheries Sector Review and Future Development Study). 2003. Theme Study: Economic performance, Fisheries Sector Review and Future Development Study. DANIDA, DFID and USAID., pp. 25-43.

Huntington, T. C. 2003. Environmental Issues in Shrimp Farming in Bangladesh. ARDMCS, Dhaka, Bangladesh. 24 pp.

Nuruzzaman, M., B. Anwary, M. Shahjahan and M. Maniruzzaman. 2001. The Dynamics and Diversity of Shrimp Farming in Bangladesh. Shrimp Sector Technical Review Fourth Fisheries Project. Dhaka, Bangladesh., pp. 1-29.

Nuruzzaman, M. and M. Maniruzzaman. 2003. Present status of coastal and marine resources of Bangladesh and future potentials for poverty alleviation: Impacts of Shrimp Farming on Coastal Communities In the proceedings of workshop on April 2003. Bangladesh Fisheries Research Forum Dhaka, Bangladesh., pp. 18-24.

UNEP. 1999. Environmental Impacts of Trade Liberalization and Policies for the Sustainable Management of Natural Resources: A Case Study on Bangladesh's Shrimp Farming Industry. UNEP, New York, USA. 45 pp.

World Bank, NACA, WWF and FAO. 2002. Shrimp Farming and the Environment: A World Bank, NACA, WWF and FAO Consortium Program to analyze and share experiences on the better management of shrimp aquaculture in coastal areas. Synthesis Report by the Consortium. $121 \mathrm{pp}$. 